\title{
Assessment of Durability Indicators of Flexible Pavements on the Basis of the Mechanical- Statistical Method
}

\author{
Artem Tiraturyan ${ }^{1, *}$, and Evgeniya Uglova $^{1}$ \\ ${ }^{1}$ Don State Technical University, Department of Highways, 1 Gagarina Square, 344000, Russia
}

\begin{abstract}
The article gives a brief overview of the developed mechanicalstatistical method of assessment of durability indicators of flexible pavements. It contains the main prerequisites of the study and the results of the study of the change in the indicators of mathematical expectation and variance of the main structural parameters of flexible pavements while in operation. Implementation of this method is illustrated with the example of calculation of the gamma-percentile remaining service life and operating life of the pavement.
\end{abstract}

Ensuring durability of flexible pavements is one of the priorities of the road sector in the Russian Federation. In terms of the theory of reliability the durability means a number of parameters including [1]:

- operating life

- gamma-percentile operating life

- mean life of the facility

- gamma-percentile service life of the facility

However, when addressing practical challenges of the road sector related to preservation of road structures, it would be more important to examine average and gamma-percentile values of the remaining service life and remaining operating life to ensure scheduling repair and prevention activities in a sound and timely manner aimed at preservation of road structures while in operation.

The matters of determining the remaining service life of the road structure with respect to the moment of occurrence of failure upon the fatigue breakdown criterion are reviewed in detail in the works [2-3]. At the same time it should be noted that the solution of this problem is considered deterministically, and as it was indicated above, only for the event of fatigue failure of asphalt concrete courses.

Meanwhile it is evident that the influence of the stochastic component on the performance of the road structure is extremely great, and the destruction process itself is characterized by the multiplicity of defects related to degradation of structural indicators of both the whole structure and its individual courses.

The research results presented in this work are aimed at formation of a new mechanicalstatistical method of assessment of road structure durability.

\footnotetext{
* Corresponding author: Tiraturjan@list.ru
} 
The existing methods for prediction of various types and kinds of fractures are based on calculation of limit values of strains or deformations in the critical points of the road structure (surface, bottom of the pack of asphalt concrete courses, base course surface, subgrade surface). In this work the scattered energy density, calculated on the basis of the hysteresis loop, drawn up with the help of mechanical-mathematical modeling tools, is determined in the critical points.

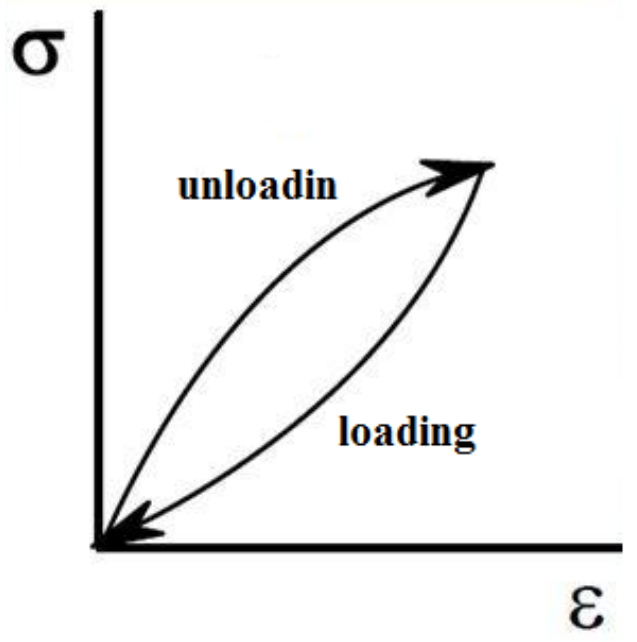

Fig. 1. Elastic hysteresis loop

The scattered energy density in this case may be calculated according to the following formula:

$$
W=\int_{0}^{\varepsilon} \sigma_{i j} d \varepsilon_{i j}, \text { with } i, j=1,2,3
$$

To calculate the loops of the dynamic hysteresis in the critical points of the pavement design the analytical model of dynamic strain-stress state of the road structure was applied for the case of the design load moving along the surface $(115 \mathrm{kN})$ and uniformly distributed along the circular wheel imprint with $800 \mathrm{kPa}$ pressure (in accordance with GOST).

To simulate the process of the load movement a moving coordinate system was introduced, based on the correspondence principle [4-5], stipulating that solution of the problem with a moving disturbance with velocity $\mathrm{V}$ is determined by numerical integration with replacement of value $\omega$ by $\omega^{*}=\omega+V \beta$ in the integration element.

Meanwhile, keeping in mind that in actual practice during interaction of a vehicle's wheel with the pavement coat a spatial dynamic stress-strain state starts to form in the pavement structure, it is appropriate to calculate the energy density according to the formula:

$$
W=\int_{0}^{\varepsilon} \sigma_{x x} d \varepsilon_{x x}+\int_{0}^{\varepsilon} \sigma_{y y} d \varepsilon_{y y}+\int_{0}^{\varepsilon} \sigma_{z z} d \varepsilon_{z z}
$$

Energy density is directly related to the two main mechanical parameters of the course its modulus of elasticity and damping factor. Solution of the problem on determination of actual values of moduli of elasticity of structure courses of flexible pavements is achieved in works [6-8]. The matters of determination of the actual parameters of the pavement's damping in the field with the use of the FWD are set forth in the work [9-10]. The possibility of identifying these parameters in the field ensured definition of the flowchart of the mechanical-statistical method of assessment of durability indicators of flexible road structures, combining algorithms of numerical simulation for determination of design 
values of a road structure service life and the results of the test measurements, making it possible to determine the values of the actual remaining service life, remaining operating life, gamma-percentile remaining service life, gamma-percentile remaining operating life at any stage of pavement operation (figures 1 to 3 ).

Input data:

Road structure:

Moduli of elasticity of courses E1.....En

Thicknesses of courses $\mathrm{h} 1 \ldots . . \mathrm{hn}$

Damping factors $\lambda 1 \ldots . . \lambda_{n}$

Longitudinal roughness IRI

Traffic load:

Total number of design load applications $-115 \mathrm{kN}$

Statistical modeling of input data on the basis of the patterns of road deterioration, established in the field
E1...En
h1..hn
$\lambda 1 \ldots . . \lambda_{0}$
IRI
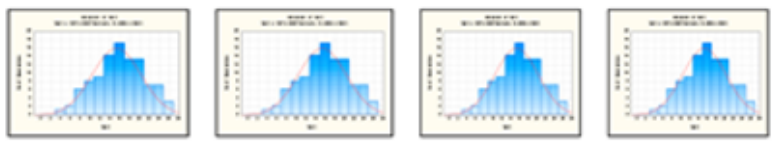

Analysis of the dynamic stress-strain state of the road structure with the use of the analytical model for the combinations of input data under examination

Calculation of the scattered energy density upon driving of a design vehicle wheel per each year of the road structure operation on the basis of the dynamic hysteresis loops, drawn up for the combinations of input data under examination in the spatial setting $W_{x x}\left(\sigma_{x x}-\varepsilon_{x x}\right)$

$$
W_{y y}\left(\sigma_{y y}-\varepsilon_{y y}\right) W_{z}\left(\sigma_{z z}-\varepsilon_{z z}\right)
$$

Summation of the scattered energy density on the road structure surface within the operating period for the combinations of input data under examination

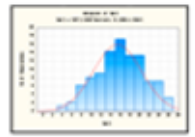

$$
\sum W_{\max }=\left(W_{x x}+W_{y y}+W_{z z}\right) \cdot \Sigma N_{p}
$$

Determination of the energy resource of the road structure of set occurrence of $95 \%$ (category I), $90 \%$ (category II), $80 \%$ (category III)

Fig. 2. Algorithm of calculation of a flexible road structure service life 


\begin{tabular}{|c|c|c|}
\hline \multicolumn{3}{|l|}{ Operating stage } \\
\hline \multicolumn{2}{|c|}{$\begin{array}{c}\text { Assessment of structural parameters of the road structure at } \\
\text { the operating stage: }\end{array}$} & \multirow{2}{*}{$\begin{array}{l}\text { Assessment of the } \\
\text { actual longitudinal } \\
\text { roughness of the road } \\
\text { structure coat }\end{array}$} \\
\hline $\begin{array}{l}\text { - modulus of elasticity of the } \\
\text { asphalt concrete course } \\
\text { - modulus of elasticity of the } \\
\text { base course } \\
\text { - modulus of elasticity of the } \\
\text { subgrade soil } \\
\text { - damping factors of the } \\
\text { courses }\end{array}$ & $\begin{array}{l}\text { - damping factor of the } \\
\text { asphalt concrete course } \\
\text { - damping factor of the } \\
\text { base course } \\
\text { - damping factor of the } \\
\text { subgrade soil }\end{array}$ & \\
\hline
\end{tabular}

Analysis of the dynamic stress-strain state of the road structure with the use of the analytica model for the actual parameters of the road structure, established at the operating stage

$$
\sigma_{x x}-\varepsilon_{x x,} \sigma_{y y}-\varepsilon_{y y} \sigma_{z z}-\varepsilon_{z z}
$$

Calculation of the scattered energy density upon driving of a design vehicle wheel per each year of the road structure operation on the basis of the dynamic hysteresis loops in the spatial setting, drawn up for the actual values of the parameters, established at the operating stage $W_{x x}\left(\sigma_{x x}-\varepsilon_{x x}\right)$ $W_{y y}\left(\sigma_{y y}-\varepsilon_{y y}\right) W_{z}\left(\sigma_{z z}-\varepsilon_{z z}\right)$

Determination of the total scattered energy density in the structure of the pavement for the operating period $\Sigma \mathrm{W}$ 'operat

Calculation of residual density of scattered energy imparted during movement of vehicles $\mathrm{W}_{\text {resid }}=\Sigma \mathrm{W}_{\text {full }}-\Sigma \mathrm{W}_{\text {, operat }}$

Determination of remaining service life, remaining operating life, gamma-percentile remaining service life, gamma-percentile operating life

Fig. 3. Algorithm of calculation of a flexible road structure service life

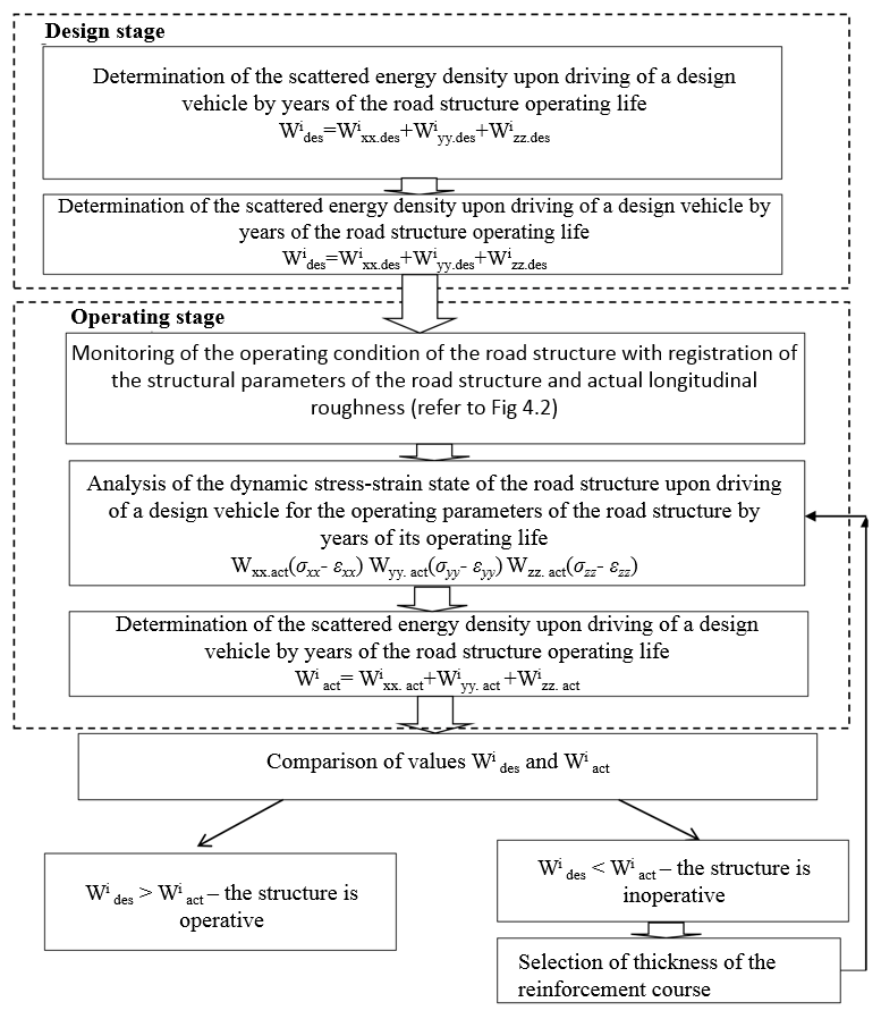

Fig. 4. Method of flexible pavement preservation on the basis of the mechanical-statistical method 
One of the key aspects, determining the efficiency of the developed method, is setting statistical parameters of distributions of main structural (moduli of elasticity, damping factors, course thicknesses) and operating parameters (longitudinal roughness of pavement). Field observations on studying these parameters were carried out from 2015 to 2018 on the sections of the federal highways with the total length of more than $2,000 \mathrm{~km}$.

During observations it was stipulated, that distribution of common moduli of elasticity, moduli of elasticity of structure courses, damping factors generally follow the lognormal law, with the mean value reduced and the variance increased during operation, which is confirmed by the results obtained in the works. Distribution of the thicknesses of pavement courses and change in the nature of their longitudinal roughness are satisfactorily fitted to the normal law of distribution.

It is commonly known, that density of the lognormal (2) distribution is fitted to the law:

$$
f(t)=\frac{1}{\sigma t \sqrt{2 \pi}} e^{-\frac{(\ln t-m)^{2}}{2 \sigma^{2}}},
$$

where $\mathrm{m}$ and $\sigma$ stand for parameters of distribution called scale parameters (mathematical expectation) and shapes of distribution (standard deviation).

The results of the field observations on studying these parameters are set forth in the following tables

Table 1. Mean values of parameters of lognormal distribution of moduli of elasticity of structure courses of road structures for various groups of sections

\begin{tabular}{|c|c|c|c|c|}
\hline Groups of $s$ & $\begin{array}{l}\text { eyed } \\
\text { tions }\end{array}$ & \multirow[t]{2}{*}{$\begin{array}{c}\text { Group I (operating life } \\
\text { less than } 5 \text { years) }\end{array}$} & \multirow[t]{2}{*}{$\begin{array}{c}\text { Group II (operating life } \\
\text { of } 5 \text { to } 10 \text { years) }\end{array}$} & \multirow[t]{2}{*}{$\begin{array}{c}\text { Group III (operating life } \\
\text { more than } 10 \text { years) }\end{array}$} \\
\hline \multicolumn{2}{|c|}{ Statistical parameter } & & & \\
\hline \multirow{2}{*}{$\begin{array}{l}\text { asphalt } \\
\text { concrete }\end{array}$} & $\mathrm{m}$ & 7.96 & 7.41 & 7.34 \\
\hline & $\sigma$ & 0.20 & 0.24 & 0.36 \\
\hline \multirow[t]{2}{*}{ base course } & $\mathrm{m}$ & 5.65 & 5.24 & 5.10 \\
\hline & $\sigma$ & 0.20 & 0.25 & 0.37 \\
\hline \multirow[t]{2}{*}{ subgrade soil } & $\mathrm{m}$ & 4.30 & 4.10 & 4.02 \\
\hline & $\sigma$ & 0.15 & 0.20 & 0.23 \\
\hline
\end{tabular}

Table 2. Mean values of parameters of lognormal distribution of damping factors of road structures for various groups of sections

\begin{tabular}{|c|c|c|c|c|}
\hline \multirow{2}{*}{\multicolumn{2}{|c|}{ Statistical parameter }} & \multirow{3}{*}{$\begin{array}{c}\text { Group I (operating life } \\
\text { less than } 5 \text { years) } \\
-2.79 \\
\end{array}$} & \multirow{3}{*}{$\begin{array}{c}\text { Group II (operating life } \\
\text { of } 5 \text { to } \mathbf{1 0} \text { years) } \\
-2.175 \\
\end{array}$} & \multirow{3}{*}{$\begin{array}{c}\text { Group III (operating life } \\
\text { more than } 10 \text { years) } \\
-1.63 \\
\end{array}$} \\
\hline & & & & \\
\hline \multirow{2}{*}{$\begin{array}{l}\text { asphalt } \\
\text { concrete }\end{array}$} & $\mathrm{m}$ & & & \\
\hline & $\sigma$ & 0.29 & 0.3375 & 0.40 \\
\hline \multirow[t]{2}{*}{ base course } & $\mathrm{m}$ & -3.54 & -3.0725 & -2.72 \\
\hline & $\sigma$ & 0.31 & 0.305 & 0.36 \\
\hline \multirow[t]{2}{*}{ subgrade soil } & $\mathrm{m}$ & -3.36 & -3.8325 & -3.49 \\
\hline & $\sigma$ & 0.25 & 0.21875 & 0.22 \\
\hline
\end{tabular}




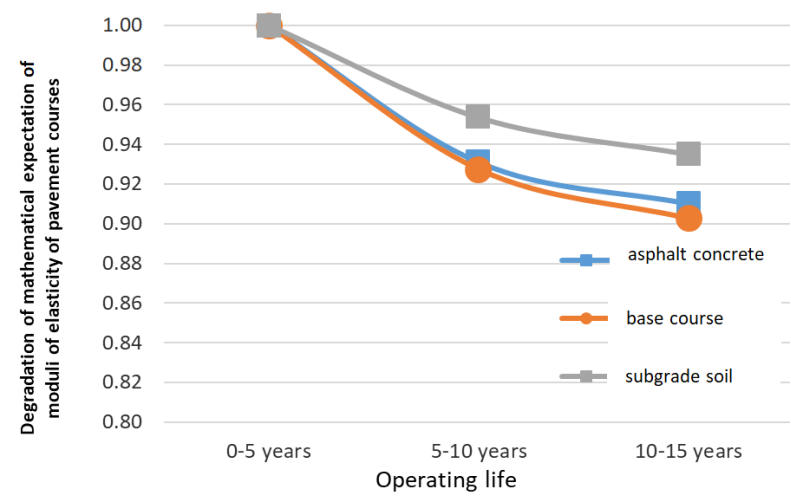

Fig. 5. Change in mathematical expectation of moduli of elasticity of structure courses of flexible pavements at the operating stage

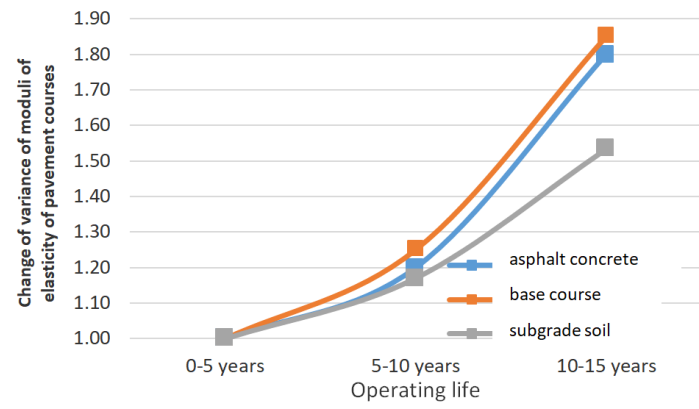

Fig. 6. Change in variance of moduli of elasticity of structure courses of flexible pavements at the operating stage

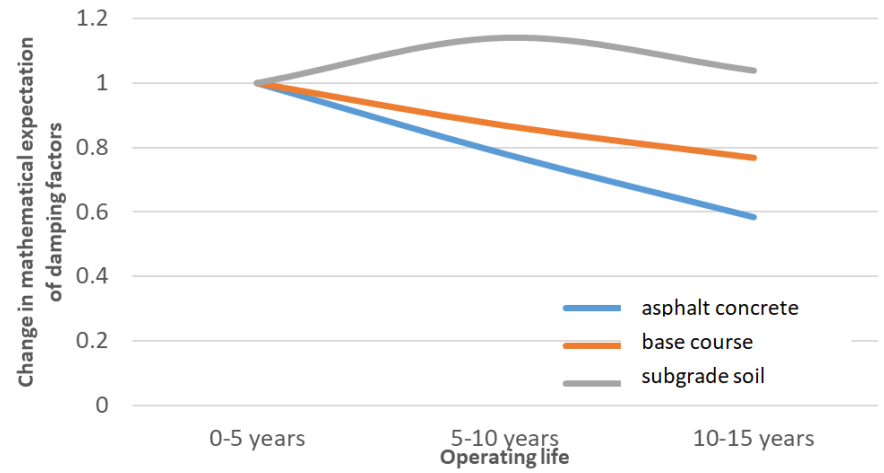

Fig. 7. Change in mathematical expectation of damping factors of structure courses of flexible pavements at the operating stage 


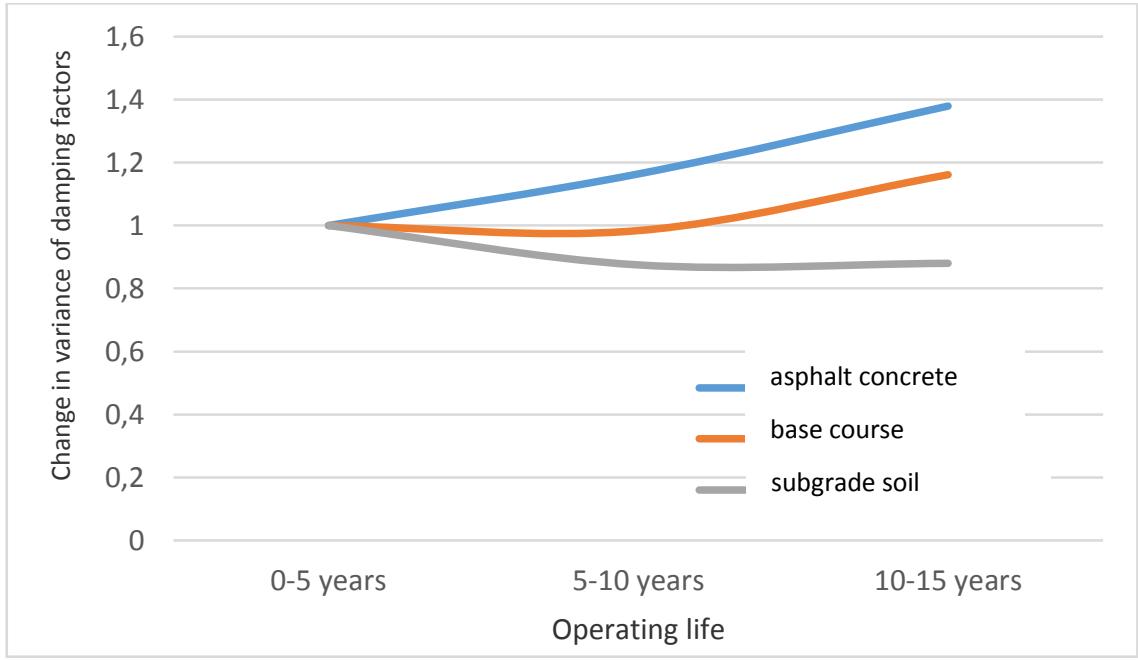

Fig. 8. Change in variance of damping factors of structure courses of flexible pavements at the operating stage

The mechanical-statistical method of assessment of flexible road structure durability was tested for the existing pavement with the design operating life of 12 years. The pavement structure includes a $20 \mathrm{~cm}$ thick pack of asphalt concrete courses, $64 \mathrm{~cm}$ base course courses, subgrade soil - clay loam.

During calculation the design values of thicknesses, moduli of elasticity and damping factors of the road structure courses were set in the form of the distribution of these parameters; and their degradation during operation was simulated on the basis of the obtained dependencies of change in the mathematical expectation and variance of the parameters in accordance with diagrams 5 to 8 . For each year of operation calculation of 5 $\%, 95 \%$ and the mean value of the design service life of the road structure (resulting in the total density of scattered energy in $\mathrm{J} / \mathrm{m}^{3}$ ) was done.

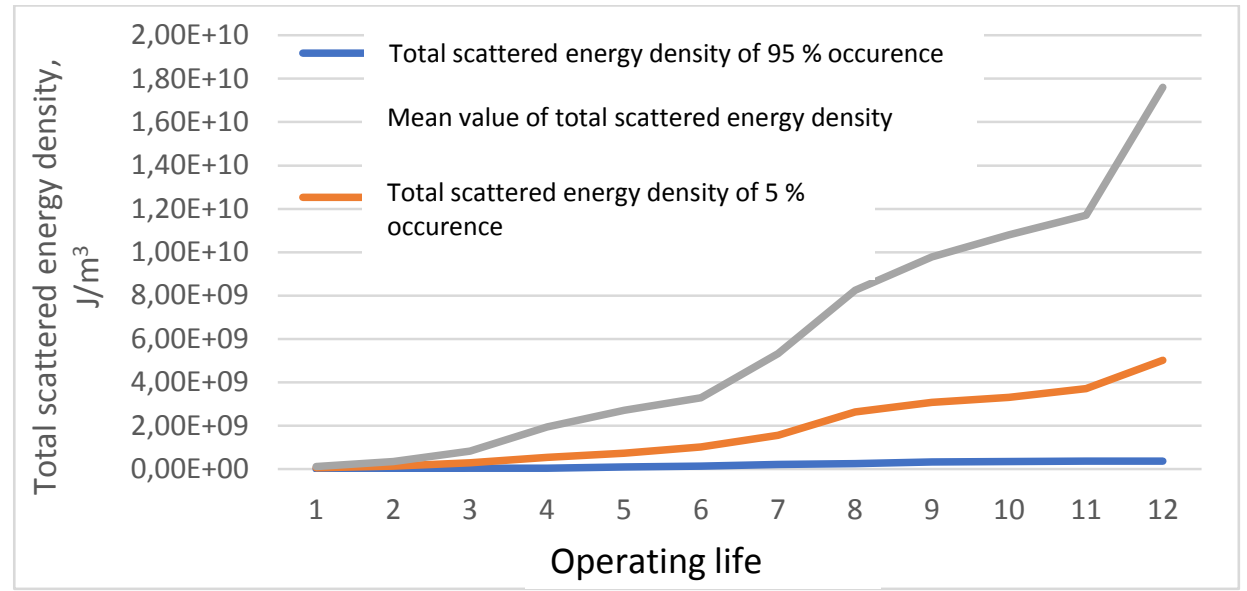

Fig. 9. Calculation of 5\%, $95 \%$ indicators and the mean value of the road structure service life 
To calculate the remaining life of the road structure at the operating stage the results of the road structure monitoring, carried out at the stage of its commissioning in 2012 and on the $5^{\text {th }}$ year of operation in 2017, were used. Based on the results of the monitoring, the actual values of the pavement's moduli of elasticity and damping factors were determined with the use of the FWD. On the basis of the obtained results calculation of the scattered energy density was done.

1 year - $13 \mathrm{MJ}($ design $-11.61 \mathrm{MJ})$

5 year - $251 \mathrm{MJ}($ design $-203.41 \mathrm{MJ})$

Thus, deviation of the design service life of the road structure of $95 \%$ occurrence from the actual one constitutes $17 \%$ in the $1^{\text {st }}$ year of operation and $24 \%$ in the $5^{\text {th }}$ year of operation. If the trend of deviation of the actual service life from the design one remains the same, the limit scope of the total scattered energy in the pavement structure constituting $2,087 \mathrm{MJ}$ will be reached already in the $10^{\text {th }}$ year of its operating life instead of the design operating life of 12 years.

It is possible to ensure the required operating life under the actual conditions by means of timely installation of a $2 \mathrm{~cm}$ thick reinforcement course made of macadam-mastic asphalt concrete. It should be noted that installation of a course with such thickness may be classified as execution of works on installation of wearing courses, i.e. section maintenance, and with the minimum operating costs it will help considerably reduce the discounted costs, arising during the pavement life cycle, at the same time ensuring the design operating life of the road structure.

\section{References}

1. A.M. Polovko, S.V. Gurov Fundamentals of the Reliability Theory. 45. (2006)

2. E.V. Uglova. Theoretical and Methodological Basis of Assessment of Remaining Fatigue Life of Asphalt Concrete Pavements of Highways. 371 (2009)

3. E.V. Uglova, B.V. Besschetnov. Bulletin of the Volgograd State Architecture and Civil Engineering University. 23103 (2011)

4. A.V. Belokon'. Dokl. AN SSSR. 261, 1079 (1981)

5. A.V. Belokon'. Prikl. matematika i mehanika. 2, 235 (1982)

6. A.N. Tiraturyan, V.V. Mizonov, A.A. Lyapin, E.V. Uglova, S.K. Iliopolov. Construction and Reconstruction. 2 (34), 88 (2011)

7. A.N. Tiraturyan, V.V. Mizonov. Science and Engineering in Road Sector. 1, 25. (2011)

8. A.N. Tiraturyan. Construction and Reconstruction. 4(42), 78 (2012)

9. A.N. Tiraturyan, E.V. Uglova. Transportation Science and Technology. 187, 742 (2017).

10. A.N. Tiraturyan, E.V.Uglova, A.A. Lyapin. PNRPU Mechanics Bulletin 2, 178 (2017) 